\title{
Morphological and histopathological study of hypertrophied inferior nasal turbinate in Egyptian patients: in clinical perspective
}

\author{
Ashraf Ali El-Demerdash¹, Essam Abdel Wanees Beheiry', Sherif Maher El-Aini², \\ Asmaa Shams El-Dein Mohamed ${ }^{3}$ and Ahmed Mohamed Ibrahim Khattab ${ }^{4^{*}}$
}

\begin{abstract}
Background: The inferior nasal turbinates have important role in the maintenance of nasal breathing function by providing the nasal valve mechanism necessary for the regulation of air flow through the nose. Hypertrophied inferior nasal turbinates are the second most common cause of chronic nasal obstruction. Our aim of this study is to evaluate the morphological and histopathological features of hypertrophied inferior nasal turbinate in Egyptian patients.
\end{abstract}

Methods: Our descriptive comparative study was carried on 30 patients presented with hypertrophied inferior nasal turbinate by clinical and radiological assessment. Patients are divided into two groups according to CT scan and endoscopic examination as group A for patients with deviated nasal septum with compensatory hypertrophied inferior nasal turbinate and group B for patients with hypertrophied inferior nasal turbinate due to allergic rhinosinusitis. Both groups underwent the same operation which partial controlled posterior inferior turbinectomy. During the period from June 2018 till May 2019, patients were selected from out-patient's clinic of Otorhinolaryngology Department at Menoufia University Hospital and Shebin El-Kom Teaching Hospital, and Military Hospital.

Results: By histopathological examination of the specimens, we found out that the bony layer thickness was more prominent in group A and the mucosal layer thickness was more prominent in group B. The prominent inflammatory cells were lymphocytes in group A and eosinophils plus mast cells in group B.

Conclusion: The bony layer thickness should be excised during the surgical treatment of cases presented with deviated nasal septum with hypertrophied inferior turbinate where in cases of allergic rhinitis with hypertrophied inferior turbinate, the mucosal layer is enough to be excised.

Keywords: Deviated nasal septum, Hypertrophied inferior turbinate, Turbinectomy

\section{Background}

The inferior turbinates (IT) have nasal valve mechanism that has an important role in regulation of air flow through the nose that lead to the maintenance of nasal breathing function [1].

Hypertrophied inferior nasal turbinates (HIT) are the second most common cause of chronic nasal obstruction.

\footnotetext{
* Correspondence: doctor.ahmed19882@gmail.com

${ }^{4}$ Department of Otolaryngology, Shebin Elkom Teaching Hospital, Shebin

El-Kom, El-Menoufia, Egypt

Full list of author information is available at the end of the article
}

Any part of the turbinates may presented with mucosal hypertrophy: its anterior part, the middle or of the last third, or simply the whole length. Mucosal hyperplasias, protrusion of the bone part and by combination of both factors, are causes for hypertrophy of the nasal turbinates [2].

There are variable etiologies for inferior turbinate hypertrophy which could be allergic rhinitis, chronic hypertrophic rhinitis, vasomotor rhinitis, chronic infective rhinitis as fungal rhinitis, and rhinitis medicamentosa [3].

\section{Springer Open}

(0) The Author(s). 2020 Open Access This article is licensed under a Creative Commons Attribution 4.0 International License, which permits use, sharing, adaptation, distribution and reproduction in any medium or format, as long as you give appropriate credit to the original author(s) and the source, provide a link to the Creative Commons licence, and indicate if changes were made. The images or other third party material in this article are included in the article's Creative Commons licence, unless indicated otherwise in a credit line to the material. If material is not included in the article's Creative Commons licence and your intended use is not permitted by statutory regulation or exceeds the permitted use, you will need to obtain permission directly from the copyright holder. To view a copy of this licence, visit http://creativecommons.org/licenses/by/4.0/. 


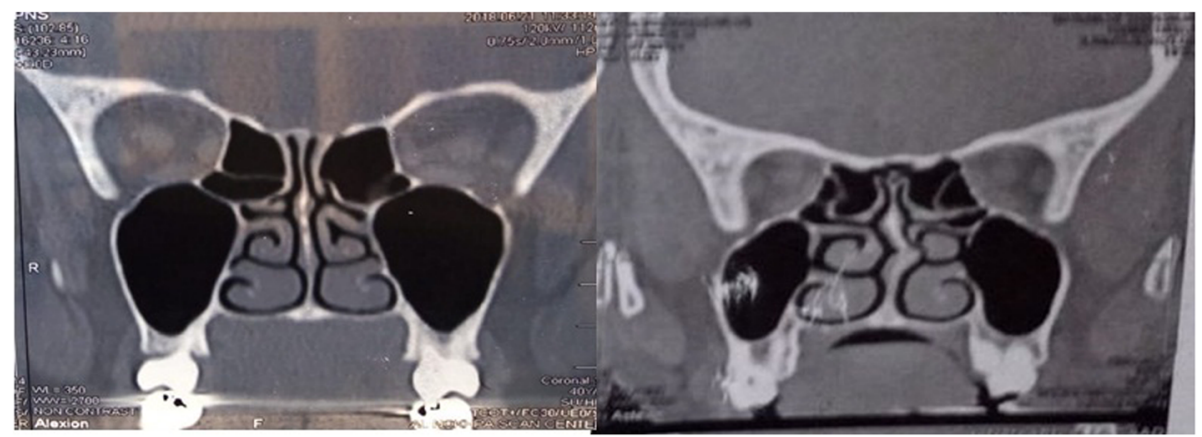

Fig. 1 CT scan of nose and paranasal sinus showing bilateral HIT on left photo while on right photo showing deviated nasal septum and HIT

Various surgical techniques have been described for the reduction of hypertrophied inferior turbinates. However, there was no definite optimal method for surgical treatment. In recent years, the minimal disturbance of the nasal mucosa has the upper hand in the surgical procedures. The aim of inferior turbinate surgery has been to maximize the volumetric reduction of the turbinate to decrease the nasal obstruction while maintaining nasal function and minimizing complications [4].

Microdebrider-assisted inferior turbinoplasty, a powered subtype of submucosal resection and radiofrequency ablation (RFA) is referred to as a mucosal sparing techniques; they are widely used and the most commonly studied techniques in the recent literature. The diode laser technique has also gained in popularity due to its ease of use in the office setting [5].

In a study, four techniques of turbinate surgery: partial inferior turbinectomy, inferior turbinoplasty, cryoturbinectomy, and laser turbinectomy were compared. The results of partial inferior turbinectomy and laser turbinectomy were superior to those of turbinoplasty and cryoturbinectomy. Each of the procedures however had their merits, limitations, and potential hazards [6].

There were few researchers studied the histopathological reports of the hypertrophied inferior turbinates and the most optimal technique of surgical interference for these patients. Such data can help surgeons determine whether to add turbinectomy as a standard procedure for surgical treatment of conditions causing HIT and which type of surgery to choose [7].

\section{Methods}

Our descriptive comparative study was carried on $30 \mathrm{pa}-$ tients with hypertrophied inferior nasal turbinate (HIT) due to either deviated nasal septum (DNS) or allergic rhinitis without nasal polypi.

Patients are divided into two groups according to computed topography (CT) scan and endoscopic examination:
* Group A: patients with DNS with compensatory HIT.

* Group B: patients with hypertrophied inferior nasal turbinate due to allergic rhinosinusitis without nasal polypi.

Ethical approval and consent to participate: consent was taken from patients before performing operation and before histopathological examination of turbinate, and they had the right to refuse at any time. The study was approved by the Research Ethics Committee of the Faculty of Medicine, Menoufa University.

Two groups undergo to the same operation which partial controlled posterior inferior turbinectomy. A written consent was taken from all patients and after approval of the ethical committee in Menoufia University Hospital. During the period from June 2018 till May 2019, patients were selected from out-patient's clinic of otorhinolaryngology department at the University Hospital according to the following inclusion and exclusion criteria:

- Inclusion criteria include patients with hypertrophied inferior nasal turbinate in allergic rhinitis and compensatory due to deviated nasal septum (DNS), patients between 18 years old and 45 years old, patients not responding to medical treatment and patients who were fit for operation according to physical examination and investigations.

- Exclusion criteria were patients with other nasal masses like nasal polyposis, nasal tumors, and any nasal granulomatous diseases.

Table 1 Complaint and clinical presentation of patients

\begin{tabular}{lll}
\hline Complaint & No. & $\%$ \\
\hline - Nasal obstruction & 30 & 100 \\
- Nasal discharge & 10 & 33.33 \\
- Headache & 5 & 16.67 \\
- Sneezing & 13 & 43.33 \\
- Epistaxis & 3 & 10 \\
\hline
\end{tabular}


Table 2 Thickness of turbinate's layers in millimeters according to histopathologic studies

\begin{tabular}{|c|c|c|c|c|c|}
\hline \multirow[t]{3}{*}{ Histopathology } & \multirow{3}{*}{ Main thickness } & \multicolumn{4}{|l|}{ Total no. of cases $=30$} \\
\hline & & Medial mucosal layer & Lateral mucosal layer & Main mucosal layer & Bony layer \\
\hline & & \multicolumn{4}{|l|}{ Mean \pm SD $(\mathrm{mm})$} \\
\hline DNS with HIT & $9.3 \pm 2.1$ & $4.3 \pm 1.5$ & $2.2 \pm 0.8$ & $8.2 \pm 4$ & $2.8 \pm 1$ \\
\hline Allergic rhinitis & $9.8 \pm 3.4$ & $5.9 \pm 1.9$ & $3 \pm 1.6$ & $9.4 \pm 3.6$ & $0.9 \pm 0.6$ \\
\hline$t$ test & 1.921 & 2.349 & 1.349 & 0.909 & 6.091 \\
\hline$P$ value & 0.237 NS & $0.033 \mathrm{~S}$ & 0.197 NS & 0.378 NS & 0.001 HS \\
\hline
\end{tabular}

$P$ value: NS non-significant ( $P$ value $>0.05), S$ significant $(P$ value $\leq 0.05), H S$ highly significant $(P$ value $\leq 0.001)$

All patients would be subjected to the following:

- Careful history taking: full personal data and full otolaryngologic symptoms.

- Full nasal and nasopharyngeal examination using anterior rhinoscopy and nasal endoscopy.

- Routine pre-operative investigations: (complete blood count, bleeding profile, liver function, kidney function).

- CT scan for nose and paranasal sinuses as shown in Fig. 1.

- Operative technique:

- Anesthesia: General anesthesia.

- Position of patient: Patient was placed in supine position, slight reverse Trendelenburg position with rotation of head of patient toward surgeon.

- Steps of operation: application of local decongestant on both nostrils would be done. Then, inferior nasal turbinate would be infractured to allow access to inferior meatus. After that, partial postero-inferior turbinectomy would be done including all the layers of the turbinate. The excision technique was done very gently not to disrupt the mucosal layer of the turbinate.

- Finally, packing would be done for each nostril.

- Ten percent buffered formaldehyde was used to preserve the specimen.

- In the department of pathology, the processed turbinate specimens were stained with hematoxylin and eosin and mounted on a glass slide for histopathological examination.

- Postoperative assessment includes:

- $>$ Clinical nasal examination

- $>$ Histopathological assessment: Biopsy specimens were taken from studied cases then paraffin blocks were prepared and 5-mm thick hematoxylin and eosin slides were evaluated by histopathological examination.

1) Qualitative assessment: lamina propria was evaluated according to proliferation of mucous



Fig. 2 Nasal turbinate showing respiratory epithelial covering (black arrow), the subepithelium is thickened by vascular spaces (red arrows) and thickened bony trabeculae (yellow) 


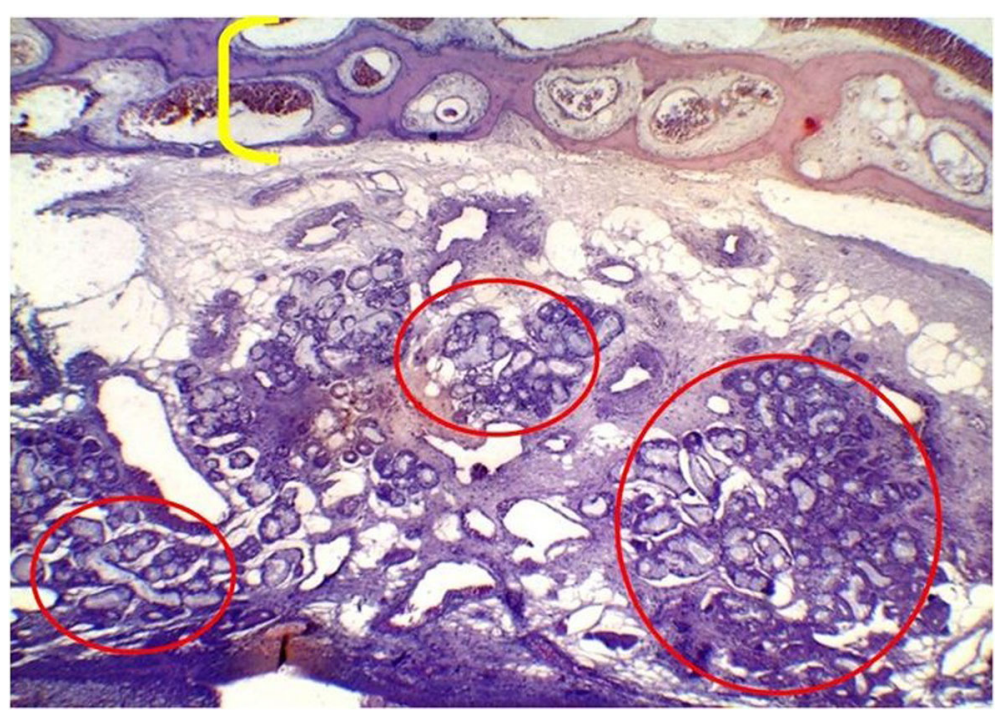

Fig. 3 Nasal turbinate showing respiratory epithelial covering, the subepithelium is thickened by mucous secreting glands (red circles) and thickened bony trabeculae (yellow)

secreting glands [mild +1 , moderate +2 , or marked +3 ], proliferation of thick-walled vascular spaces [mild +1 , moderate +2 , or marked +3 ] density of chronic inflammatory infiltrate [mild +1 , moderate +2 , or marked +3 ], and fibrosis [mild +1 , moderate +2 , or marked +3 ].

2) Quantitative assessment: dimensions of main mucosal thickness, medial mucosal layer, lateral mucosal layer, and thickness of bony layer were evaluated by standard morphometric measures using slide micrometer.

\section{Results}

In this study, the mean age of patients was $27 \pm 6.4$ years, $63.34 \%$ of patients were female and $36.66 \%$ of patients were male.

In this study, all patients presented with nasal obstruction (100\%), sneezing was present in 13 patients (43.3\%), nasal discharge was present in 10 patients (33.3\%), headache was present in 5 patients $(16.6 \%)$ while epistaxis was present in 3 patients (10\%) as shown in Table 1.
After assessment of these cases by nasal examination and CT, 8 cases showed unilateral hypertrophied IT, while 22 cases presented with bilateral HIT. Thirteen cases showed DNS with compensatory hypertrophied IT and 17 cases had allergic rhinitis.

According to this study, the main thickness and lateral mucosal layer thickness showed non-significant differences in both groups, but the medial mucosal layer thickness showed significant differences in both groups in addition to that the bony layer thickness showed highly significant differences in both groups as shown in Table 2 and Figs. 2 and 3.

By histopathological examination of the specimens of inferior turbinates, there are no significant differences between both groups according to the presence of mucosal glands and engorged sinusoids. The prominent inflammatory cells were lymphocytes in group A and eosinophils plus mast cells in group $\mathrm{B}$ as shown in Tables 3 and 4 and in Fig. 4.

According to complications occurred after each procedures performed, 3 cases presented with nasal bleeding

Table 3 Mucosal and submucosal layers of studies specimens

\begin{tabular}{|c|c|c|c|c|c|c|}
\hline \multicolumn{2}{|c|}{ Mucosal and submucosal layers } & \multicolumn{2}{|c|}{ DNS with HIT } & \multicolumn{2}{|c|}{ Allergic rhinitis } & \multirow[t]{2}{*}{$P$ value } \\
\hline & & No. & $\%$ & No. & $\%$ & \\
\hline \multirow[t]{3}{*}{ Mucosal layer hyperplasia } & Mild & 3 & 23 & 3 & 18 & \multirow[t]{3}{*}{$0.301 \mathrm{NS}$} \\
\hline & Moderate & 9 & 69 & 5 & 29 & \\
\hline & Marked & 1 & 8 & 9 & 53 & \\
\hline \multirow[t]{3}{*}{ Sub-mucosal blood vessels } & Mild & 2 & 15 & 1 & 6 & \multirow[t]{3}{*}{$0.667 \mathrm{NS}$} \\
\hline & Moderate & 4 & 30 & 5 & 30 & \\
\hline & Marked & 7 & 55 & 11 & 64 & \\
\hline
\end{tabular}

$P$ value: NS non-significant $(P$ value $>0.05), S$ significant $(P$ value $\leq 0.05) H S$ highly significant $(P$ value $\leq 0.001)$ 
Table 4 Inflammatory cells in our studied specimens

\begin{tabular}{lll}
\hline Inflammatory cells & DNS with HIT & Allergic rhinitis \\
\hline Mast cells & Not prominent & Prominent \\
Lymphocytes & Prominent & Not prominent \\
Esinophils & Not prominent & Prominent \\
\hline
\end{tabular}

plus only one case had synechia after septoplasty with unilateral turbinectomy, 2 cases had synechia plus only one case had nasal crustations after septoplasty with bilateral turbinectomy, and 4 cases presented with bilateral nasal bleeding, 3 cases had crustations plus 2 cases presented with infections after bilateral turbinectomy as shown in Table 5.

\section{Discussion}

Nasal obstruction is a very common symptom in otorhinolaryngology practice, which affects patient's personal social family and professional life and needs systematic approach in management. Turbinate reduction surgery is based on the increase in nasal air way volume will facilitate better functional nasal airflow, which in turn will produce improvement in patient symptom [5].

In bilateral turbinate enlargement, there is evidence for a mucosal contribution to enlargement. Histological studies suggest that a combination of mechanisms may be responsible for mucosal enlargement, including cellular hyperplasia, tissue edema, and vascular congestion. There is no evidence for cellular hypertrophy [7].

In our research, we found out that the mean age of 30 patients with nasal obstruction due to hypertrophied inferior nasal turbinate was $27 \pm 6.4$ years, $63.34 \%$ of patients were female and $36.66 \%$ of patients were male. While Al-Sharhan et al. found out that the mean age was $34.6 \pm 15.3$ years old, $95.9 \%$ of patients were male and $4.1 \%$ of patients were female and Berger et al. showed that the mean age in patients with hypertrophied inferior nasal turbinates was 35 years old $[8,9]$.
As in our study, we found out that main complaint in our patients was nasal obstruction. As well as Bhat et al. studied 100 cases with HIT and showed that percentage of patients' complaint was nasal obstruction (100\%), 26 cases only with nasal discharge, 15 cases only presented with headache and 32 cases complained of sneezing [10].

In our results, 13 cases showed DNS with compensatory hypertrophied IT and 17 cases had allergic rhinitis. While Hegazy et al. studied 10 cases with DNS with compensatory HIT and another 10 cases with allergic rhinitis [11].

According to this results, main thickness of the IT was $9.3 \pm 2.1 \mathrm{~mm}$ in patients with DNS plus HIT and $9.8 \pm$ $3.4 \mathrm{~mm}$ in patients with allergic rhinitis. Medial mucosal layer thickness was $4.3 \pm 1.5 \mathrm{~mm}$ and $5.9 \pm 1.9 \mathrm{~mm}$ in patients with DNS plus HIT and patients with allergic rhinitis consequently compared with lateral mucosal layer thickness that was $2.2 \pm 0.8$ and $3 \pm 1.6$ in patients with DNS plus HIT and patients with allergic rhinitis consequently. Bony layer thickness was $2.8 \pm 1$ in patients having DNS with HIT and $0.9 \pm 0.6$ in patients with allergic rhinitis. Bhat et al. said that mean total thickness (width) of inferior turbinate in DNS with HIT group was $5.27 \pm 0.98 \mathrm{~mm}$ and in allergic rhinitis group was $5.05 \pm 0.60 \mathrm{~mm}$. Berger $G$ et al. showed that the mean width of turbinate were $3.82 \pm 0.48 \mathrm{~mm}$ and 5.16 $\pm 0.82 \mathrm{~mm}$ in control group and DNS with HIT group respectively $[10,12]$.

By histopathological examination of the specimens of IT, we found out that mucosal glands were markedly increased in allergic rhinitis. Seven cases only with engorged sinusoids in DNS with HIT, while 11 cases (64\%) had engorged sinusoids in allergic rhinitis. According to inflammatory cells, eosinophils, and mast cells were the prominent inflammatory cells in allergic rhinitis group. While lymphocytes and plasma cells were the prominent inflammatory cells in DNS with HIT group, Berger et al. agreed with our results [9].

Hegazy et al. examined 20 specimens of IT related to 2 groups of DNS with HIT and allergic rhinitis groups

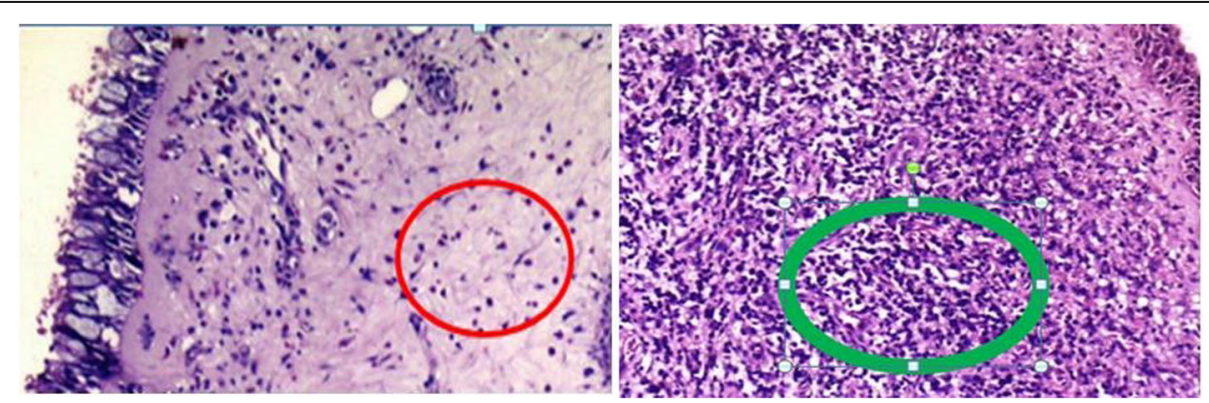

Fig. 4 Nasal turbinate showing eosinophils and plasma cell infiltrate in HIT with AR (red circle) while in DNS and HIT, the subepithelium is densely infiltrated by lymphocytes (green) 
Table 5 Complications according to procedures performed

\begin{tabular}{lllll}
\hline $\begin{array}{l}\text { Complications according to procedures } \\
\text { performed }\end{array}$ & $\begin{array}{l}\text { Septoplasty with unilateral } \\
\text { turbinectomy }\end{array}$ & $\begin{array}{l}\text { Septoplasty with bilateral } \\
\text { turbinectomy }\end{array}$ & $\begin{array}{l}\text { Bilateral turbinectomy without } \\
\text { septoplasty }\end{array}$ & $\begin{array}{l}P \\
\text { value }\end{array}$ \\
\hline Hemorrhage & 3 & 0 & 4 & 0.968 \\
Crustations & 0 & 1 & 3 & NS \\
Synechia & 1 & 2 & 0 & 2 \\
Infection & 0 & 0 &
\end{tabular}

$P$ value: $N S$ non-significant $(P$ value $>0.05), S$ significant $(P$ value $\leq 0.05) H S$ highly significant $(P$ value $\leq 0.001)$

and found out that both groups had congested venous sinusoids that could be associated with rupture and hemorrhage. Hegazy et al. also showed that lymphocytes and plasma cells were prominent inflammatory cells in both groups, but esinophils were more prominent in allergic rhinitis [11].

According to fibrosis in lamina propria, Bhat et al. showed that only $27.2 \%$ of specimens in DNS with HIT group showed this fibrosis compared with only $11 \%$ of specimens in allergic rhinitis group. According to the most prominent inflammatory cells, the mast cells and eosinophils were prominent in allergic rhinitis group, where as in DNS with HIT group lymphocytes were prominent cells [10].

Millas et al. found out that there was no statistically significant difference in the distribution pattern of the glandular epithelium of the lamina propria [13].

\section{Conclusion}

It was found that partial inferior turbinectomy for cases of hypertrophied inferior turbinate secondary to deviated nasal septum and allergic rhinitis is effective in relieving symptom of nasal obstruction.

The bony layer thickness should be excised during the surgical treatment of cases presented with deviated nasal septum with hypertrophied inferior turbinate where in cases of allergic rhinitis with hypertrophied inferior turbinate, the mucosal layer is enough to be excised.

\section{Abbreviations}

CT: Computed tomography; DNS: Deviated nasal septum; H\&E: Hematoxylin and eosin; HIT: Hypertrophied inferior nasal turbinate; IT: Inferior turbinate; RFA: Radiofrequency ablation

\section{Acknowledgements}

Not applicable

\section{Authors' contributions}

AK collected patients from outpatient clinic and was responsible for the design and analyzing data and share in writing the manuscript. AE was a major contributor in writing the manuscript. EB analyzed and interpreted the patient data regarding the diagnosis and management of the cases. SM done partial posterior turbinectomy with or without septoplasty to the cases. AM performed the histological examination of the turbinate and analyzed the date. All authors read and approved the final manuscript.

\section{Funding}

There was no funding
Availability of data and materials

The datasets used and/or analyzed in the current study are available from the corresponding author on reasonable request.

\section{Ethics approval and consent to participate}

Consent was taken from patients before performing operation and before histopathological examination of turbinate, and they had the right to refuse at any time. The study was approved by the Research Ethics Committee of the Faculty of Medicine, Menoufa University. Ethics committee reference number is 4/2018ENT/135.

\section{Consent for publication}

Not applicable.

\section{Competing interests}

The authors declare that they have no competing interests in this section.

\section{Author details}

${ }^{1}$ Department of Otolaryngology, Faculty of Medicine, Menoufia University, Shebin El-Kom, Menoufia, Egypt. ${ }^{2}$ Department of Otolaryngology, Military Medical Academy, Shebin el-kom, Menoufia, Egypt. ${ }^{3}$ Department of Pathology, Faculty of Medicine, Menoufia University, Shebin El-Kom, Menoufia, Egypt. ${ }^{4}$ Department of Otolaryngology, Shebin Elkom Teaching Hospital, Shebin El-Kom, El-Menoufia, Egypt.

Received: 29 March 2020 Accepted: 22 July 2020

Published online: 21 October 2020

\section{References}

1. Kang SH, Lim S, Oh D, Kang K, Jung KJ, Kim HK, Lee SH, Baek SK, Kim TH (2015) Clinical feasibility trial of 1,940-nm diode laser in Korean patients with inferior turbinate hypertrophy. Med Lasers 4(2):60-64

2. Novak V, Miroslav C, Jon G (2017) Utility of submucosal turbinoplasty for the treatment of chronic nasal obstruction. Glob J Oto 11(2):151-154

3. Bofares KM (2015) Dilemma of inferior turbinate surgery. Adv Surg Sci 3(2):8-18

4. Harju T, Numminen J, Kivekas I, Rautiainen M (2018) A prospective randomized, placebo-controlled study of inferior turbinate surgery. Laryngoscope:1531-4995

5. Sinno S, Mehta K, Lee ZH, Kidwai S, Saadeh PB, Lee MR (2016) Inferior turbinate hypertrophy in rhinoplasty: systematic review of surgical techniques. Plast Reconstr Surg 138:419e-429e

6. Elwany S, Harrison R (1990) Inferior turbinectomy: comparison of four techniques. J Laryngol Otol 104:206-209

7. Farmer SEJ, Eccles R (2006) Chronic inferior turbinate enlargement and the implications for surgical intervention. Rhinology. 44:234-238

8. Al Sharhan SS, Lee EJ, Hwang CS, Nam JS, Yoon JH, Kim CH et al (2018) Radiological comparison of inferior turbinate hypertrophy between allergic and non-allergic rhinitis: does allergy really augment turbinate hypertrophy. Eur Arch Otorhinolaryngol 275(4):923-929

9. Berger G, Gass S, Ophir D (2006) The histopathology of the hypertrophic inferior turbinate. Arch Otolaryngol Head Neck Surg 132:588-593

10. Bhat V (2010) Histopathological study of hypertrophied inferior turbinate (doctoral dissertation)

11. Hegazy MA, Mohamed AS, El-Hennawy AY, El-Fouly MS (2014) Histopathological study of hypertrophic inferior turbinate. Egypt Otolaryngol 30(1):23 
12. Berger G, Azim MB, Ophir D (2003) The normal inferior turbinate: histomorphometric analysis and clinical implications. Laryngoscope. 113:1992-1998

13. Millas I, Maria BL, Eduardo JD, Tavares JH, Fregnani G, Macéa JR (2009)

Histological analysis of the distribution pattern of glandular tissue in normal inferior nasal turbinates. Braz J Otorhinolaryngol 75(4):507-510

\section{Publisher's Note}

Springer Nature remains neutral with regard to jurisdictional claims in published maps and institutional affiliations.

Submit your manuscript to a SpringerOpen ${ }^{\circ}$ journal and benefit from:

- Convenient online submission

- Rigorous peer review

- Open access: articles freely available online

- High visibility within the field

- Retaining the copyright to your article

Submit your next manuscript at $\boldsymbol{\wedge}$ springeropen.com 